\title{
PENINGKATAN KEGIATAN OPERASIONAL KLINIK PRATAMA AL-IKHLAS MUHAMMADIYAH BOROBUDUR
}

\author{
Nur Hidayah'), Mahendro Prasetyo Kusumo2) \\ 1)Magister Administrasi Rumah Sakit, Program Pascasarjana, Universitas Muhammadiyah Yogyakarta, Bantul, \\ DI Yogyakarta, Indonesia \\ 2)Program Studi Pendidikan Dokter, Fakultas Kedokteran, Universitas Muhammadiyah Yogyakarta, Bantul, \\ DI Yogyakarta, Indonesia \\ Corresponding author: Nur Hidayah \\ E-mail: nurhidayah@umy.ac.id
}

Diterima 27 Januari 2021, Direvisi 27 Februari 2021, Disetujui 28 Februari 2021

\begin{abstract}
ABSTRAK
Kegiatan operasional sebuah klinik yang berjalan sesuai dengan ketentuan yang telah ditetapkan dalam peraturan perundang-undangan dan kebijakan pemilik mendukung tercapainya visi dan misi klinik. Tujuan dari kegiatan pengabdian masyarakat ini adalah meningkatkan kegiatan operasional Klinik Pratama Al-Ikhlas Muhammadiyah Borobudur untuk memperbaiki kinerja klinik yang selama beberapa tahun terakhir mengalami penurunan. Metode yang digunakan adalah studi kasus menggunakan observasi partisipatif dengan mensinergikan kegiatan pengabdian masyarakat dosen Magister Administrasi Rumah Sakit Universitas Muhammadiyah Yogyakarta dengan kegiatan operasional Klinik Al-Ikhlas Muhammadiyah Borobudur (Klinik) bekerja sama dengan Ranting Aisyiyah Borobudur 3 dan Cabang Borobudur. Hasil dari pengabdian masyarakat adalah peningkatan kegiatan operasional klinik dalam memberikan pelayanan kesehatan kepada masyarakat terutama warga Muhammadiyah dan Aisyiyah Borobudur dan warga masyarakat yang berada di sekitar klinik. Hasil dari pengabdian masyarakat yang lain adalah peningkatan motivasi dari sumber daya manusia klinik untuk memperbaiki kinerjanya sehingga klinik dapat menjalankan fungsinya dengan baik.
\end{abstract}

Kata kunci: peningkatan; kegiatan operasional; kinerja; klinik pratama.

\begin{abstract}
The clinic's operational activities that work according to the provisions that have been set in regulations and stakeholder policy can support the clinic to achieve the clinic's vision and mission. This community service aimed to improve the operational activities of Klinik Pratama Al-Ikhlas Muhammadiyah Borobudur, especially in improving the clinic's performance which decreases in recent years. The method applied was a case study using participatory observation by synergizing both the community service of the master of Hospital administration lecturers, Universitas Muhammadiyah Yogyakarta, and clinics operational of Klinik Pratama Al-Ikhlas Muhammadiyah Borobudur which collaborate with Aisyiyah Borobudur Branch 3 and Borobudur Branch. The result of this community service was the improvement of the clinic's operational activities in providing health service to the community, especially the residents of Muhammadiyah dan Aisyiyah Borobudur and also the residents around the clinic. Besides, another result of the community service was the enhancement of the motivation of clinical human resources to improve the clinical performance, so the clinic can carry out its function properly.
\end{abstract}

Keywords: improvement; operational activities; performance; pratama clinic.

\section{PENDAHULUAN}

Data tahun 2013 menunjukkan bahwa sebanyak 121 juta manusia ( $47 \%$ dari populasi) tidak memiliki akses kesehatan yang memadai disebabkan adanya sistem pembiayaan dan asuransi kesehatan yang terfragmentasi (Agustina et al., 2019). Masyarakat berharap dapat mengakses perawatan kesehatan yang berkualitas dengan harga terjangkau (Jin et al., 2020) mengingat sebagian masyarakat tidak mampu membayar biaya perawatan kesehatan yang mereka butuhkan (Meng et al., 2015). Hal tersebut kemudian menjadi pertimbangan pemerintah Indonesia untuk melaksanakan reformasi sistem kesehatan yang diharapkan dapat menjadi upaya untuk mewujudkan kesehatan yang adil dan efektif untuk semua manusia atau Universal Health Coverage (UHC) (Meng et al., 2019). Pemerintah Indonesia telah melaksanakan reformasi sistem kesehatan yang dibuktikan dengan adanya perencanaan UHC yang dirancang oleh pemerintah Indonesia sejak tahun 2002 dan baru mulai terealisasi pada tahun 2014 (Agustina et al., 2019). 
Pemerintah Indonesia telah memberlakukan program Jaminan Kesehatan Nasional untuk mencapai UHC yang dikenal dengan Sistem Asuransi Kesehatan Nasional atau Jaminan Kesehatan Nasional (JKN) (Agustina et al., 2019). Untuk menyelenggarakan JKN dibentuklah sebuah badan yang disebut Badan Penyelenggara Jaminan Sosial Kesehatan (BPJS). Namun, pada implementasi Program JKN masih terdapat beberapa tantangan yang dihadapi oleh penyedia pelayanan kesehatan dalam memberikan pelayanan kepada peserta JKN yang bekerjasama dengan BPJS. Tantangan tersebut antara lain, jumlah dan kualitas fasilitas perawatan primer yang tidak memadai, ketersediaan obat-obatan dan peralatan medis yang tidak mencukupi, adanya ketidaktepatan sasaran kelompok yang berpenghasilan rendah dan menengah, adanya masalah pelanggaran, dan sistem informasi kesehatan yang buruk (Agustina et al., 2019).

Perawatan kesehatan Tingkat Pertama atau Primary Health Care (PHC) terdiri atas Puskesmas, Klinik Pratama, dan dokter keluarga. Selain itu, Perawatan Kesehatan Primer atau PHC merupakan salah satu institusi layanan kesehatan yang telah dipercaya sebagai sarana yang ditujukan untuk mengatasi kesenjangangan kesehatan hampir di semua negara (Gauld et al., 2012). Klinik Pratama AlIkhlas Muhammadiyah Borobudur (selanjutnya disebut Klinik) merupakan salah satu PHC yang sudah berdiri sejak lama, yaitu sejak tahun 1980-an. Pada awalnya, klinik sempat berkembang sampai pada pelayanan rawat inap, tetapi dikarenakan manajemen yang kurang tepat, kurangnya biaya, dan sumber daya manusia sehingga klinik tidak terawat. Selain itu, sejak diberlakukannya JKN, pemerintah mengeluarkan kebijakan baru agar seluruh masyarakat menjadi peserta JKN dengan membayar premi asuransi melalui BPJS. Namun sangat disayangkan, klinik belum bisa bekerjasama dengan BPJS sehingga klinik hanya menerima pasien umum dalam jumlah yang sangat terbatas. Ada beberapa hal yang menyebabkan klinik belum dapat beroperasi secara normal, (1) surat ijin operasioanl klinik belum berhasil diperpanjang karena suatu kendala teknis, (2) tiga orang dokter sedang dalam proses pembuatan SIP, (3) dana operasional yang tidak mencukupi, dan 4) jumlah pasien sedikit. Dengan demikian, masih banyak permasalahan yang dihadapi oleh klinik dalam memberikan pelayanan kesehatan kepada masyarakat. Berdasarkan permasalahan yang dihadapi tersebut, program pengabdian masyarakat yang dilakukan oleh dua orang dosen Magister Administrasi Rumah Sakit Program Pascasarjana Universitas
Muhammadiyah Yogyakarta (MARS UMY) ini ditujukan untuk mencari solusi yaitu upaya meningkatkan kembali kegiatan operasional klinik.

\section{METODE}

Program pengabdian masyarakat ini bertempat di Klinik Pratama Al-Ikhlas Muhammadiyah Borobudur yang berlokasi di $\mathrm{Jl}$. Badrawati No 6 Borobudur Magelang. Mitra dari program pengabdian masyarakat ini adalah Klinik Pratama Al-lkhlas Muhammadiyah Borobudur yang terdiri dari Pimpinan Klinik, Ketua Pimpinan Cabang Muhammadiyah (PCM) Borobudur, dan Dokter Penanggungjawab Klinik. Metode yang digunakan dalam kegiatan pengabdian masyarakat ini adalah metode studi kasus melalui observasi partisipatif dengan mensinergikan kegiatan pengabdian masyarakat dosen MARS UMY, operasional klinik, dan kegiatan Ranting Aisyiyah Borobudur Tiga serta Cabang Aisyiyah Borobudur. Kegiatan ini sekaligus mempromosikan Klinik Al-Ikhlas Muhammadiyah Borobudur kepada anggota Ranting Aisyiyah Cabang Aisyiyah Borobudur. Pelaksanaan kegiatan pengabdian masyarakat dilakukan dengan cara: (1) memberikan ceramah tentang pentingnya peningkatan kegiatan operasional klinik, (2) menjelaskan perlunya keterlibatan pimpinan dan anggota Aisyiyah sebagai salah satu pemangku kepentingan klinik, (3) penyuluhan kesehatan dan ceramah agama Islam, memberikan pemeriksaan dan pengobatan gratis bagi peserta yang memerlukan, dan (4) memberikan sumbangan sebuah alat pemeriksaan tekanan darah, dua alat pemeriksaan gula darah, cholesterol, dan asam urat (GCU) yang dilengkapi dengan obatobatan yang diperlukan. Adapun jumlah subjek yang diteliti dalam program pengabdian masyarakat ini terdiri dari 40 responden.

\section{HASIL DAN PEMBAHASAN Hasil}

Dari hasil studi pendahuluan diperoleh gambaran bahwa klinik belum bekerjasama dengan BPJS sehingga jumlah pasien sangat sedikit. Dengan demikian, pendapatan klinik tidak dapat menutup biaya operasional. Kekuarangan biaya operasional ditanggung oleh Pimpinan Cabang Muhammadiyah (PCM) Borobudur. Adapun tenaga kesehatan yang bekerja di klinik hanya terdiri atas seorang dokter umum (dalam proses perpanjangan SIP), dua orang bidan, seorang perawat, dan seorang tenaga kebersihan yang merangkap bekerja sebagai petugas antarjemput siswa merangkap petugas administrasi Sekolah Dasar Muhammadiyah Borobudur. Dua orang 
dokter sedang dalam proses pengurusan Surat ljin Praktek (SIP) dengan tempat praktik menggunakan alamat yang sama dengan klinik. Dalam melakukan kegiatan pengabdian masyarakat ini, juga dibagikan kuesioner kepada peserta dengan hasil yang ditunjukkan pada Tabel 1 sampai Tabel 4 berikut ini.

Tabel 1. Intensitas Kunjungan Pasien ke Klinik Pratama Al-Ikhlas Muhammadiyah Borobudur.

\begin{tabular}{|c|c|c|}
\hline Pertanyaan & Skala & $\begin{array}{c}\text { Persentase } \\
\text { (\%) }\end{array}$ \\
\hline \multirow[t]{4}{*}{$\begin{array}{c}\text { Apakah ibu } \\
\text { sudah pernah } \\
\text { berkunjung ke } \\
\text { Klinik Pratama } \\
\text { Al-Ikhlas } \\
\text { Muhammadiyah } \\
\text { Borobudur? }\end{array}$} & $\begin{array}{l}\text { Pernah } \\
\text { sekali }\end{array}$ & $15 \%$ \\
\hline & $\begin{array}{l}\text { Pernah } \\
\text { dua kali }\end{array}$ & $5 \%$ \\
\hline & $\begin{array}{l}\text { Pernah } \\
\text { lebih dari } \\
\text { dua kali }\end{array}$ & $55 \%$ \\
\hline & $\begin{array}{l}\text { Belum } \\
\text { pernah }\end{array}$ & 25 \\
\hline
\end{tabular}

Berdasarkan tabel intensitas kunjungan pasien ke Klinik Pratama Al-Ikhlas Muhammadiyah Borobudur tersebut, menunjukkan bahwa responden pernah berkunjung ke klinik baik baru sekali, dua kali, atau lebih dari dua kali mencapai presentase sebesar $75 \%$. Hal ini karena sebenarnya klinik tersebut sudah berdiri sejak 1987 dan pernah menjadi rumah bersalin rawat inap yang menangani banyak pasien. Namun, seharusnya izin operasionalnya diperpanjang setiap lima tahun sekali, tetapi dalam kenyataannya tidak diperpanjang. Izin operasional terakhir tahun 2009, kemudian tahun 2014, dan 2019 tidak diperpanjang. Pada tahun 2017 sudah mengajukan perpanjangan izin operasional tetapi Dokter Penanggung Jawab Klinik pindah tugas di rumah sakit dan tidak ada penggantinya sehingga klinik tidak dapat beroperasi sebagaimana seharusnya. Pada 10 Maret 2020, dilakukan pengecekan ke Dinas Kesehatan Kabupaten Magelang, Bagian Perizinan, semua berkas perizinan operasional yang sudah diserahkan dikembalikan ke klinik karena sudah banyak peraturan yang berubah sejak tahun 2017 hingga tahun 2020. Prosedur pengajuannya pun sudah berubah. Kini, perizinan diajukan ke Dinas Penanaman Modal dan Pelayanan Terpadu Satu Pintu (DPMPTSP) Kabupaten Magelang. Setelah menemui petugas DPMPTSP, diberitahukan bahwa ada berkas yang masih bisa digunakan dan ada berkas yang sudah tidak dapat digunakan. Namun demikian, Klinik Pratama Al-Ikhlas Muhammadiyah Borobudur tidak dapat langsung mengurus izin operasional, tetapi terlebih dahulu harus mengurus izin pendirian klinik. Dengan berbagai upaya, kini dokter dengan SIP lengkap sudah ada tiga orang ditambah dua orang bidan dan seorang perawat.

Tabel 2. Penggunaan Asuransi Kesehatan.

\begin{tabular}{|c|c|c|}
\hline Pertanyaan & Skala & $\begin{array}{c}\text { Persentase } \\
(\%)\end{array}$ \\
\hline \multirow[t]{2}{*}{$\begin{array}{c}\text { Apakah anda } \\
\text { sudah pernah } \\
\text { menggunakan } \\
\text { BPJS untuk } \\
\text { berobat? }\end{array}$} & Sudah & $92,5 \%$ \\
\hline & Belum & $7,5 \%$ \\
\hline
\end{tabular}

Berdasarkan Tabel 2 tentang penggunaan asuransi kesehatan tersebut, hampir semua responden dari kegiatan pengabdian masyarakat ini telah terdaftar sebagai peserta BPJS (Badan Penyelenggara Jaminan Sosial). Hal tersebut bisa dilihat dari perbandingan 2 skala yang terdiri dari skala sudah dan belum. Dari kedua skala tersebut, skala "sudah" mempunyai persentase mayoritas yaitu sebesar 92,5\%. Selebihnya dalam jumlah yang sangat kecil belum menggunakan Asuransi Kesehatan BPJS dengan persentase $7,5 \%$.

Tabel 3. Pemanfaatan Fasilitas Kesehatan.

\begin{tabular}{|c|c|c|}
\hline Pertanyaan & Skala & $\begin{array}{l}\text { Persentase } \\
\text { (\%) }\end{array}$ \\
\hline \multirow[t]{4}{*}{$\begin{array}{c}\text { Apabila ibu } \\
\text { sudah } \\
\text { menjadi } \\
\text { peserta } \\
\text { BPJS, } \\
\text { dimana } \\
\text { tempat } \\
\text { berobat } \\
\text { pertama } \\
\text { ketika ibu } \\
\text { sakit? } \\
\end{array}$} & Puskesmas & $37,5 \%$ \\
\hline & $\begin{array}{c}\text { Klinik } \\
\text { Pratama } \\
\end{array}$ & $2,5 \%$ \\
\hline & $\begin{array}{c}\text { BKIA } \\
\text { Borobudur }\end{array}$ & $5 \%$ \\
\hline & $\begin{array}{c}\text { Dokter } \\
\text { Praktik } \\
\text { Pribadi/ } \\
\text { Dokter } \\
\text { Keluarga }\end{array}$ & $55 \%$ \\
\hline
\end{tabular}

Dari tabel 3, ditunjukkan bahwa dari semua responden dari kegiatan pengabdian 
masyarakat ini, sebagian besar lebih dari 50 persen berobat ke dokter praktik pribadi/dokter keluarga, kemudian baru ke Puskesmas, sedangkan responden yang berobat ke Klinik Pratama Al-lkhlas Muhammadiyah Borobudur hanya mencapai 2,5-5 persen. Hal ini karena Klinik Pratama Al-Ikhlas Muhammadiyah Borobudur belum bekerjasama dengan BPJS, sedangkan sebagian besar responden adalah anggota BPJS sehingga pasien yang berkunjung ke klinik adalah pasien umum yang jumlahnya masih sedikit. Ditambah lagi dengan adanya Covid-19, mulai 17 Maret 2020 klinik ditutup dua bulan karena belum mempunyai alat pelindung diri (APD) tenaga kesehatan dan desinfektan yang mencukupi. Akhirnya, pada tanggal 2 Juni 2020 Klinik mulai dibuka kembali dengan SIP dokter dari tiga orang dokter. Klinik Pratama Al-lkhlas Muhammadiyah Borobudur adalah klinik yang didirikan dan diselenggarakan oleh Pimpinan Cabang Muhammadiyah (PCM) Borobudur dan dikelola oleh MPKU (Majelis Pembina kesehatan Umum).

Tabel 4. Harapan dan Saran bagi Klinik Pratama Al-lkhlas Muhammadiyah Borobudur.

\begin{tabular}{cc}
\hline No. & Harapan dan Saran \\
\hline 1 & $\begin{array}{c}\text { Meningkatkan aspek pelayanan } \\
\text { kesehatan }\end{array}$ \\
\hline 2 & $\begin{array}{c}\text { Meningkatkan aspek fasilitas } \\
\text { kesehatan }\end{array}$ \\
\hline 3 & $\begin{array}{c}\text { Bekerjasama dengan BPJS (Badan } \\
\text { Penyelenggara Jaminan Sosial) }\end{array}$ \\
\hline 4 & $\begin{array}{c}\text { Mempromosikan BKIA Al-Ikhlas PKU } \\
\text { Muhammadiyah Borobudur ke } \\
\text { Masyarakat }\end{array}$ \\
\hline 5 & Adanya dokter yang memenuhi \\
kualifikasi
\end{tabular}

Hal ini menjadi masukan yang sangat penting bagi Klinik Pratama Al Ikhlas Muhammadiyah Borobudur untuk meningkatkan kegiatan operasionalnya. Pada akhir kegiatan pengabdian kepada masyarakat, harapan dan saran tersebut sebagian sudah terwujud, tiga orang dokter sudah mempunyai SIP (Surat lijin Praktek) sesuai dengan tempat Klinik Al-Ikhlas yaitu Jl. Badrawati No 6, Ngaran 1, Borobudur, Kabupaten Magelang. Dengan demikian, aspek manajemen pelayanan operasional sudah dapat ditingkatkan dengan seorang dokter merangkap tugas sebagai Penanggungjawan Klinik dan Medis, seorang dokter penanggung kerja sama, seorang dokter pelaksana, seorang bidan merangkap sebagai bagian administrasi dan keuangan, seorang bidan yang merangkap sebagai penanggung jawab obat, dan seorang perawat yang merangkap sebagai penanggung jawab kebersihan, peralatan medis, dan sarana prasarana klinik. Namun, karena belum ada izin pendirian dan izin operasional klinik, praktik dokter menggunakan SIP dokter yang bertugas. Selain itu, Pimpinan Cabang Muhammadiyah (PCM) dan Pimpinan Cabang Aisyiyah (PCA) Borobudur saat ini juga telah mempunyai berbagai amal usaha seperti amal usaha yang bergerak di bidang pendididikan mulai dari pendidikan usia dini (PAUD), Taman Kanak-Kanak Bustanul Athfal (TK ABA), sekolah dasar (SD), sekolah menengah pertama (SMP), sekolah menengah kejuruan (SMK), dan sekolah menengah atas (SMA) dan juga amal usaha di bidang kemasyarakatan berupa panti asuhan putra dan panti asuhan putri. PCM Borobudur juga sedang merintis pendirian pesantren putra. Harapannya, klinik dapat bekerjasama dengan amal-amal usaha tersebut dalam meningkatkan kegiatan operasional klinik dengan cara melakukan kunjungan penyuluhan dan pengobatan secara berkala, serta menerima kunjungan dari siswasiswa dan guru-guru, dan anak-anak panti asuhan yang memerlukan pelayanan kesehatan. Untuk saat ini, Klinik Pratama AlIkhlas Muhammadiyah Borobudur belum dapat mempromosikan kegiatan operasional klinik langsung kepada masyarakat, ditambah lagi dalam masa pandemi Covid-19 sehingga untuk sementara kegiatan promosi dilakukan melalui media sosial seperti WhatsApp.

Adapun rencana melakukan kerja sama dengan BPJS masih menunggu izin operasional klinik atau menggunakan SIP dokter penanggung jawab dan menunggu terbitnya izin operasional klinik agar biaya operasional klinik dapat ditingkatkan dengan adanya kapitasi dari BPJS. Dengan adanya Covid-19 mulai 17 Maret 2020 Klinik terpaksa ditutup karena alat pelindung diri (APD) sulit didapatkan di pasaran dan harganya sangat mahal. Dengan melakukan lobi dan mencari informasi usaha mendapatkan APD dan antiseptik, akhirnya mendapat bantuan APD dan antiseptik dari berbagai lembaga Muhammadiyah dan Aisyiyah. Kemudian, tanggal 2 Juni 2020, klinik dapat buka kembali dengan protokol kesehatan. Kecamatan Borobudur, Kabupaten Magelang sempat termasuk zona merah (banyak pasien yang dinyatakan positif terinfeksi Covid-19) sehingga jumlah pasien yang berobat ke Klinik sangat sedikit sebagaimana juga penurunan jumlah pasien yang terjadi di pelayanan kesehatan lainnya. 


\section{Pembahasan}

Klinik merupakan salah satu dari Fasilitas Kesehatan Tingkat Pertama (FKTP) atau Primary Health Care (PHC) yang dalam praktiknya harus berpedoman pada peraturan perundang-undangan yang telah berlaku. Berdasarkan Peraturan Menteri Kesehatan Nomor 028/MENKES/PER/I/2011 tentang Klinik menjelaskan bahwa klinik adalah fasilitas pelayanan kesehatan yang berperan dalam memberikan pelayanan kesehatan perorangan yang menyelenggarakan pelayanan medis dasar dan atau spesialistik, diselenggarakan oleh lebih dari satu jenis tenaga kesehatan dan dipimpin oleh seorang tenaga medis. Adapun tenaga medis terdiri dari dokter, dokter spesialis, dokter gigi, dan dokter gigi spesialis, sedangkan tenaga kesehatan adalah setiap orang yang mengabdikan diri dalam bidang kesehatan dan memiliki pengetahuan dan keterampilan melalui pendidikan di bidang kesehatan untuk jenis tertentu membutuhkan kewenangan dalam melakukan upaya kesehatan (Kementerian Kesehatan, 2011). Dengan diberlakukannya perundang-undangan terkait pelayan kesehatan, klinik yang beroperasi di Indonesia dapat menjadikan perundang-undangan tersebut sebagai pedoman dalam mengelola klinik sehingga dapat meningkatkan kegiatan operasional klinik. Kinik perlu mengambil langkah-langkah dalam mengelola klinik untuk meningkatkan kegiatan operasional klinik. Hal tersebut mengingat bahwa kegiatan operasional dapat memberikan dampak yang signifikan terhadap pemberian perawatan pasien terutama dalam mengembangkan sistem kesehatan tanpa biaya operasional yang tinggi (Carter et al., 2012).

Langkah pertama yaitu dengan cara melakukan perbaikan terkait kelengkapan sumber daya manusia (SDM). Dalam meningkatkan kegiatan operasional klinik, kelengkapan dari SDM harus memenuhi standar yang telah ditetapkan berdasarkan perundang-undangan yang berlaku. Adapun SDM yang dimaksud yaitu Tenaga Medis dan Tenaga Kesehatan yang dimiliki oleh sebuah klinik harus terdaftar secara hukum untuk menjalankan praktik pelayanan kesehatan. Dalam Peraturan Menteri Kesehatan Nomor 9 Tahun 2014 Pasal 13 juga telah disebutkan bahwa setiap tenaga medis yang berpraktik di klinik harus mempunyai Surat Tanda Registrasi (STR) dan Surat Izin Praktik (SIP) sesuai ketentuan peraturan perundang-undangan. Demikian halnya bagi setiap tenaga kesehatan lain yang bekerja di klinik juga harus mempunyai Surat Tanda Registrasi (STR), dan Surat Izin Kerja atau Surat Izin Praktik (SIP) sesuai dengan peraturan perundang-undangan (Kementerian Kesehatan, 2014).

Berdasarkan Undang-Undang Republik Indonesia Nomor 36 Tahun 2014 Pasal 1 tentang Tenaga Kesehatan dijelaskan bahwa STR merupakan bukti tertulis yang diberikan oleh konsil masing-masing kepada tenaga kesehatan yang telah diregistrasi, sedangkan SIP merupakan bukti tertulis yang diberikan oleh pemerintah daerah kabupaten atau kota kepada tenaga kesehatan sebagai pemberian kewenangan untuk menjalankan praktik (Undang-Undang Republik Indonesia Nomor 36 Tahun 2014 Tentang Tenaga Kesehatan, 2014). Dengan demikian, baik tenaga medis maupun tenaga kesehatan lainnya wajib memiliki STR dan SIP dalam menjalankan praktik pelayanan kesehatan. Berdasarkan Undang-Undang Republik Indonesia Nomor 36 Tahun 2014 Pasal 44, terdapat beberapa persyaratan yang harus dipenuhi oleh tenaga medis maupun tenaga kesehatan lainnya terkait STR, di antaranya memiliki ijazah pendidikan di bidang kesehatan, memiliki Sertifikat Kompetensi, memiliki surat keterangan sehat fisik dan mental, memiliki surat pernyataan telah mengucapkan sumpah/ janji profesi, dan bersedia membuat pernyataan untuk mematuhi dan melaksakan ketentuan etika profesi. Apabila semua persyaratan tersebut terpenuhi, tenaga medis dan tenaga kesehatan lainnya berhak mendapatkan STR dari Konsil masingmasing tenaga kesehatan dengan masa berlaku 5 tahun dan dapat diregistrasi ulang. Adapun persyaratan registrasi ulang adalah memiliki STR lama, memiliki Sertifikat Kompetensi atau Sertifikat Profesi, memiliki surat keterangan sehat fisik dan mental, bersedia membuat pernyataan untuk mematuhi dan melaksanakan ketentuan etika profesi, telah mengabdikan diri sebagai tenaga profesi/ vokasi di bidangnya, dan memenuhi kecukupan dalam kegiatan pelayanan, pendidikan, pelatihan, dan atau kegiatan ilmiah lainnya.

Selain itu, ketentuan perizinan SIP telah diatur dalam Undang-Undang Republik Indonesia Nomor 36 Tahun 2014 Pasal 46 yang menjelaskan bahwa ada beberapa persyaratan yng harus dipenuhi oleh tenaga medis dan tenaga kesehatan untuk mendapatkan SIP, di antaranya memiliki STR yang masih berlaku, rekomendasi dari organisasi profesi, dan tempat praktik. Adapun SIP hanya bisa digunakan untuk 1 tempat praktik dalam catatan STR masih berlaku dan tempat praktik masih sesuai dengan yang tercantum dalam SIP. Akhirnya, klinik dengan tiga orang dokter yang sudah mempunyai STR dan SIP, dibantu oleh dua orang bidan dan seorang perawat sudah dapat melaksanakan kegiatan operasional dengan 
baik, tetapi terkendala adanya Covid-19. Dengan demikian, klinik mengalami kesulitan untuk melakukan promosi secara langsung melalui berbagai kegiatan bersama masyarakat atau amal-amal usaha Muhammadiyah dan Aisyiyah. Masalah lain yang terjadi adalah dengan adanya Covid-19, biaya operasional klinik meningkat karena harus menyiapkan alat pelindung diri dan antiseptik untuk dapat melaksanakan pelayanan kesehatan dengan protokol pencegahan Covid-19. Namun, jumlah pasien menurun karena masyarakat takut datang ke pelayanan kesehatan kecuali memang dalam keadaan darurat.

Langkah kedua yaitu bekerja sama dengan BPJS. Pada dasarnya, setiap manusia mempunyai hak yang sama untuk mendapatkan akses pelayanan kesehatan yang aman, bermutu, dan terjangkau (Undang-Undang Republik Indonesia Nomor 36 Tahun 2014 Tentang Tenaga Kesehatan, 2014). Dalam mewujudkan hal tersebut, pemerintah telah melakukan reformasi sistem kesehatan dengan memberlakukan kebijakan kesehatan nasional guna meningkatkan kinerja sistem kesehatan secara keseluruhan (Argaw et al., 2020). Pemerintah Indonesia telah menerapan sistem JKN yang dirancang dengan menggabungkan sistem asuransi kesehatan dan bantuan sosial yang terfragmentasi menjadi satu intetitas publik yaitu BPJS (Agustina et al., 2019). Selain Pemerintah Indonesia, Pemerintah di beberapa Negara juga sudah lama menerapkan Sistem Asuransi Kesehatan Nasional guna untuk mewujudkan UHC. Pada tahun 2005, pemerintah Ghana mengeluarkan kebijakan untuk mewajibkan semua warga negara dan penduduk Ghana untuk berlangganan Sistem Asuransi Kesehatan Nasional sebagaimana tercantum dalam Amandemen Undang-Undang 852 tahun 2012 (Republik of Ghana, 2012). Selain itu, sejak awal tahun 2019, China juga mulai menerapkan upaya terkait reformasi kesehatan dalam rangka mewujudkan UHC pada tahun 2020 (Meng et al., 2015). Adanya reformasi kesehatan tersebut dirasa cukup berhasil dalam mengatasi masalah ketidakadilan dalam bidang kesehatan. Adapun reformasi sistem kesehatan utama yang telah diadopsi di China saat ini, yaitu melakukan penguatan terkait skema asuransi kesehatan sosial, melakukan integrasi terkait penyedia layanan kesehatan, melakukan reformasi terkait sektor rumah sakit umum, mengadopsi mekanisme pembelian strategis, dan meningkatkan kualitas perawatan kesehatan (Meng et al., 2015).

Pemerintah Indonesia telah menetapkan kebijakan-kebijakan terkait sistem JKN yang telah diatur dalam undang-undang terkait bidang kesehatan. Berdasarkan Undangundang Republik Indonesia Nomor 40 tahun 2004 tentang Sistem Jaminan Sosial Nasional (SJSN) menjelaskan bahwa setiap orang berhak atas jaminan sosial untuk dapat memenuhi kebutuhan dasar hidup yang layak dan meningkatkan martabatnya demi mewujudkan masyarakat Indonesia yang sejahtera, adil, dan makmur (Kementerian Kesehatan, 2004). Selain itu, pemerintah Indonesia menetapkan SJSN dalam rangka memberikan jaminan sosial yang menyeluruh bagi rakyat Indonesia (Kementerian Kesehatan, 2004). Oleh sebab itu, berdasarkan Pasal 5 ayat (1) dan Pasal 52 Undang-Undang dalam rangka menyelenggarakan program jaminan sosial Nomor 40 Tahun 2004 tentang Sistem Jaminan Sosial Nasional (Kementerian Kesehatan, 2004), pemerintah membentuk badan hukum yang dinamakan Badan BPJS sebagaimana yang telah diatur dalam Undang-undang Republik Indonesia Nomor 24 Tahun 2011 tentang badan Penyelenggara Jaminan Nasional. Adapun peserta JKN terdiri atas Peserta Bantuan luran (PBI) dan peserta JKN mandiri (baik pekerja maupun bukan pekerja). Adapun Peserta Bantuan luran (PBI) adalah bantuan yang dibayarkan oleh pemerintah dengan menggunakan dana Anggaran Pendapatan dan Belanja Negara (APBN) bagi fakir miskin dan masyarakat yang tidak mampu (PERMENKES, 2011). Selain itu, peserta mandiri merupakan peserta JKN yang secara mandiri membayarkan sejumlah uang secara teratur (PERMENKES, 2011). Besaran iuran asuransi kesehatan yang dibayarkan melalui BPJS oleh peserta JKN telah ditetapkan oleh menteri kesehatan. Adapun klinik sebagai salah satu Fasilitas Kesehatan Tingkat Pertama (FKTP) (Badan Penyelenggara Jaminan Sosial (BPJS) Kesehatan, 2015). Oleh karena itu, besaran iuran asuransi kesehatan yang dibayar yaitu berdasarkan kapitasi atas jumlah peserta yang terdaftar di FKTP sebagaimana yang termuat dalam Peraturan BPJS Kesehatan Nomor 2 Tahun 2015 tentang Norma Penetapan Besaran Kapitasi dan Pembayaran Kapitasi Berbasis Pemenuhan Komitmen Pelayanan pada fasilitas Kesehatan Tingkat Pertama.

Besaran tarif kapitasi yang dibayarkan kepada FKTP di suatu wilayah ditetapkan berdasarkan kesepakatan BPJS Kesehatan dengan Asosiasi Fasilitas Kesehatan di wilayah setempat dengan mengacu pada standar tarif kapitasi yang telah ditetapkan oleh Menteri Kesehatan. Penetapan tarif kapitasi tersebut ditetapkan oleh BPJS kesehatan kabupaten/kota berdasarkan seleksi dan kredensialing (uji kelayakan) dengan mempertimbangkan beberapa aspek yang 
terdiri atas sumber daya manusia, kelengkapan sarana dan prasarana, lingkup pelayanan, dan komitmen pelayanan (Badan Penyelenggara Jaminan Sosial (BPJS) Kesehatan, 2015). Dengan diberlakukannya perundang-undangan terkait Sistem JKN, klinik sebagai FKTP wajib bekerja sama dengan BPJS, kemudian bagi klinik yang belum bekerja sama dengan BPJS seharusnya segera menyusun rencana dan mempersiapkan persyaratan yang dibutuhkan agar bisa bekerja sama dengn BPJS. Apabila klinik tidak bekerja sama dengan BPJS, pendapatan klinik yang diperoleh dari pasien umum yang jumlahnya sangat sedikit tidak akan dapat memenuhi kebutuhan biaya operasional klinik. Sebelum klinik memperoleh izin pendirian dan operasional, dokter penanggung jawab klinik dapat menggunakan SIP dan persyaratan lainnya untuk membuka praktek dokter yang bekerja sama dengan BPJS. Ketika klinik sudah memenuhi syarat untuk bekerja sama dengan BPJS, hal tersebut dapat diatur sedemikian rupa apakah tetap mempertahankan prakter dokter ditambah dengan klinik yang bekerja sama dengan BPJS atau peserta JKN yang sudah terdaftar di praktek dokter dipindahkan ke klinik. Semakin banyak peserta dengan tiga orang dokter, misalnya dapat mencapai 15 ribu peserta, kegiatan operasional klinik juga semakin baik, cakupannya semakin luas, dan manfaatnya semakin banyak dirasakan oleh masyarakat.

\section{SIMPULAN DAN SARAN}

Meningkatkan kegiatan operasional suatu klinik merupakan suatu hal yang sangat penting karena hal tersebut akan berpengaruh terhadap perkembangan klinik. Sama halnya dengan meningkatkan kegiatan operasional Klinik Al-lkhlas Muhammadiyah Borobudur, tentunya juga membutuhkan beberapa usaha, salah satunya yaitu dengan cara pendekatan dan memperkenalkan klinik kepada masyarakat sekitar. Harapannya ketika klinik sudah bekerja sama dengan BPJS, masyarakat menjadikan klinik tersebut sebagai fasilitas kesehatan tingkat pertama dalam sistem rujukan pelayanan kesehatan JKN. Dengan demikian, klinik pratama wajib untuk bekerja sama dengan BPJS karena tidak dapat mengandalkan pasien umum yang jumlahnya sangat sedikit untuk menopang kegiatan operasional klinik. Melalui kerja sama dengan BPJS, klinik mendapatkan dana kapitasi per peserta, ditambah lagi sebagian besar masyarakat sudah menjadi peserta JKN baik yang Peserta Bantuan luran (PBI) maupun peserta JKN mandiri.

\section{UCAPAN TERIMAKASIH}

Dalam kesempatan kali ini, penulis ingin menyampaikan ucapan terimakasih kepada Lembaga Penelitian, Publikasi, dan Pengabdian Masyarakat (LP3M) Universitas muhammadiyah Yogyakarta yang telah mendukung dalam pelaksanaan kegiatan program pengabdian masyarakat ini. Selain itu, penulis juga berterimakasih kepada Lembaga Penelitian, Publikasi, dan Pengabdian Masyarakat (LP3M) Universitas Muhammadiyah Yogyakarta yang telah memberikan kesempatan kepada penulis dalam mengikuti Seminar Nasional Program Pengabdian Masyarakat "Inovasi Teknologi dan Pengembangan Teknologi Informasi dan Pemberdayaan Masyarakat Pasca Covid-19".

\section{DAFTAR RUJUKAN}

Agustina, R., Dartanto, T., Sitompul, R., Susiloretni, K. A., Suparmi, Achadi, E. L., Taher, A., Wirawan, F., Sungkar, S., Sudarmono, P., Shankar, A. H., Thabrany, H., Susiloretni, K. A., Soewondo, P., Ahmad, S. A., Kurniawan, M., Hidayat, B., Pardede, D., Mundiharno, ... Khusun, H. (2019). Universal health coverage in Indonesia: Concept, progress, and challenges. The Lancet, 393(10166), 75-102. https://doi.org/10.1016/S01406736(18)31647-7

Argaw, M. D., Desta, B. F., Kibret, M. A., Abebe, M. G., Heyi, W. K., Mamo, E., Gebru, T., Gelan, C., Tefera, B. B., \& Bele, T. A. (2020). Accelerating the performance of district health systems towards achieving UHC via twinning partnerships. BMC Health Services Research, 20(1), 892. https://doi.org/10.1186/s12913-02005741-1

Badan Penyelenggara Jaminan Sosial (BPJS) Kesehatan. (2015). Peraturan Badan Penyelenggara Jaminan Sosial Kesehatan Nomor 2 Tahun 2015 tentang norma penetapan besaran kapitasi dan pembayaran kapitasi berbasis pemenuhan komitmen pelayanan pada fasilitas kesehatan tingkat pertama. Animal Genetics, 39(5), 561-563.

Carter, P. M., Desmond, J. S., Akanbobnaab, C., Oteng, R. A., Rominski, S. D., Barsan, W. G., \& Cunningham, R. M. (2012). Optimizing clinical operations as part of a global emergency medicine initiative in Kumasi, Ghana: Application of lean manufacturing principals to lowresource health systems. Academic Emergency Medicine, 19(3), 338-347. 
https://doi.org/10.1111/j.1553-

2712.2012.01311.x

Gauld, R., Blank, R., Burgers, J., Cohen, A. B., Dobrow, M. K., Ikegami, N. K. I., Kwon, S., Luxford, K., Milett, C., \& Wendt, C. (2012). The World Health report 2008Primary healthcare: How wide is the gap between its agenda and implementation in 12 high-income health systems? Healthcare Policy, 7(3), 38-58. https://doi.org/10.12927/hcpol.2013.22 778

Jin, Y., Xu, J., Zhu, W., Zhang, Y., Xu, L., \& Meng, Q. (2020). Synergy of policies to strengthen primary care: Evidence from a national repeated cross-sectional study. BMC Health Services Research, 2O(1), 865. https://doi.org/10.1186/s12913-02005695-4

Kementerian Kesehatan. (2004). UndangUndang RI Nomor 40 Tahun 2004 Tentang Sistem Jaminan Sosial Nasional. $\quad$ XXXIII(2), 81-87. https://doi.org/10.1007/s13398-0140173-7.2

Kementerian Kesehatan. (2011). Peraturan Menteri Kesehatan Republik Indonesia Nomor 028 Tahun 2011. Kementerian Kesehatan.

https://luk.staff.ugm.ac.id/atur/Permen kes28-2011.pdf

Kementerian Kesehatan. (2014). Peraturan Menteri Kesehatan Republik Indonesia Nomor 9 Tahun 2014 Tentang Klinik (Vol. 11, Issue c). Kementerian Kesehatan.

Meng, Q., Mills, A., Wang, L., \& Han, Q. (2019). What can we learn from China's health system reform? The BMJ, 365, 1-5. https://doi.org/10.1136/bmj.12349

Meng, Q., Yang, H., Chen, W., Sun, Q., \& Liu, X. (2015). People's Republic of China Health System Review. Health Systems in Transition, 5(7), 16.

PERMENKES. (2011). UU Republik Indonesia nomor 24 Tahun 2011. Kementerian Kesehatan. https://bpjskesehatan.go.id/bpjs/dmdocuments/20 e67493084e6d2e600888b1dd9f94f4.p df

Republik of Ghana. (2012). National Health Insurance ACT 2012 (ACT 852). Republik of Ghana. http://www.nhis.gov.gh/files/ACT852.p df

Undang-Undang Republik Indonesia Nomor 36 Tahun 2014 tentang Tenaga Kesehatan. (2014). 